\title{
The Lateral Habenula Circuitry: Reward Processing and Cognitive Control
}

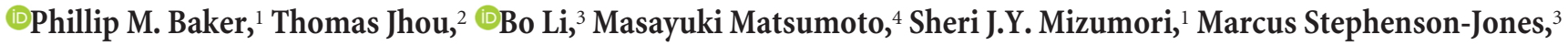 \\ and Aleksandra Vicentic ${ }^{5}$ \\ ${ }^{1}$ Department of Psychology, University of Washington, Seattle, Washington 98195-1525, ${ }^{2}$ Medical University of South Carolina, Department of \\ Neurosciences, Charleston, South Carolina 29425, ${ }^{3}$ Cold Spring Harbor Laboratory, Cold Spring Harbor, New York 11724 , ${ }^{4}$ Division of Biomedical Science, \\ Faculty of Medicine, University of Tsukuba, Ibaraki 305-8577, Japan, and ${ }^{5}$ Division of Neuroscience and Basic Behavioral Science, National Institute of \\ Mental Health, Rockville, Maryland 20892
}

There has been a growing interest in understanding the role of the lateral habenula (LHb) in reward processing, affect regulation, and goal-directed behaviors. The LHb gets major inputs from the habenula-projecting globus pallidus and the $\mathrm{mPFC}$, sending its efferents to the dopaminergic VTA and SNc, serotonergic dorsal raphe nuclei, and the GABAergic rostromedial tegmental nucleus. Recent studies have made advances in our understanding of the LHb circuit organization, yet the precise mechanisms of its involvement in complex behaviors are largely unknown. To begin to address this unresolved question, we present here emerging cross-species perspectives with a goal to provide a more refined understanding of the role of the LHb circuits in reward and cognition. We begin by highlighting recent findings from rodent experiments using optogenetics, electrophysiology, molecular, pharmacology, and tracing techniques that reveal diverse neural phenotypes in the $\mathrm{LHb}$ circuits that may underlie previously undescribed behavioral functions. We then discuss results from electrophysiological studies in macaques that suggest that the LHb cooperates with the anterior cingulate cortex to monitor action outcomes and signal behavioral adjustment. Finally, we provide an integrated summary of cross-species findings and discuss how further research on the connectivity, neural signaling, and physiology of the LHb circuits can deepen our understanding of the role of the LHb in normal and maladaptive behaviors associated with mental illnesses and drug abuse.

Key words: anterior cingulate cortex; cognition; globus pallidus; lateral habenula; punishment; reward; rostromedial tegmental nucleus

\section{Introduction}

The habenula is a complex anatomical region nestled in the epithalamus that is comprised of the medial (MHb) and lateral (LHb) nuclei. In particular, the LHb has received substantial research attention because of its involvement in processing of reward and aversive information, cognitive flexibility, and emotion (Hikosaka et al., 2008; Zhao et al., 2015). Dysfunctions of the LHb have been implicated in mental illnesses associated with maladaptive processing of positive and negative valence stimuli (Proulx et al., 2014); thus, it is important to understand molecular, cellular, and circuit interactions of the LHb circuits that may contribute to these disorders.

Received July 25, 2016; revised Sept. 23, 2016; accepted Sept. 26, 2016.

This work was supported by National Institute of Drug Abuse Grant T32 DA07278 - 20 to P.M.B., National Institute of Mental Health Grant R01MH108924 to B.L., National Institute of Drug Abuse Grants 1R01DA037327 and National Institute on Drug Abuse 1R21DA032898 to T.J., Cabinet Office, Government of Japan Funding Program for Next Generation World-Leading Researchers LS074, Ministry of Education, Culture, Sports, Science and Technology of Japan Grants-in-Aid for Scientific Research 26120707, Takeda Science Foundation, Inamori Foundation, and Uehara Memorial Foundation to M.M., National Institute of Mental Health Grant R01MH58755 and University of Washington Research Royalty Fund Grant to S.J.Y.M., and National Alliance for Research on Schizophrenia and Depression and EMBO Long-Term Fellowship Awards to M.S.-J.

The authors declare no competing financial interests.

Correspondence should be addressed to Dr. Aleksandra Vicentic, Division of Neuroscience and Basic Behavioral Science, National Institute of Mental Health, Rockville, MD 20892. E-mail: vicentica@mail.nih.gov; or Dr. Bo Li, Cold Spring Harbor Laboratory, Cold Spring Harbor, NY 11724. E-mail: bli@cshl.edu.

DOI:10.1523/JNEUROSCI.2350-16.2016

Copyright $\odot 2016$ the authors $\quad 0270-6474 / 16 / 3611482-07 \$ 15.00 / 0$
The $\mathrm{LHb}$ receives inputs from several forebrain limbic circuits involved in motivation and value processing and sends outputs to brainstem centers involved in prediction of aversive events and behavioral inhibition (Kim and Lee, 2012). The LHb is activated by aversive stimuli and reward omission and is inhibited by unexpected rewards, with the activation preceding inhibition of dopaminergic (DA) neurons (Matsumoto and Hikosaka, 2007). In an elegant set of experiments, exposure of mice to aversive stimuli was shown to augment the LHb excitatory inputs onto rostromedial tegmental nucleus (RMTg) neurons, whereas optogenetic activation of this pathway promoted behavioral avoidance (Stamatakis and Stuber, 2012). Furthermore, the specific RMTg projections to the VTA are activated following exposure to aversive stimuli and inhibited by those that signal reward (Jhou et al., 2009a), supporting the role of LHb-RMTg-VTA connections in aversive behaviors. In another study using viral-mediated tracing with electrophysiology and optogenetic manipulations, LHb inputs to the VTA were also shown to elicit aversive behaviors (Lammel et al., 2012). These observations in rodents were extended by findings that nonhuman primate brains have a similar structure to rat RMTg that receives excitatory input from the $\mathrm{LHb}$ and exhibits negative reward-prediction errors (PEs) (Hong et al., 2011). This further suggests that the LHb-RMTg circuit is involved in transmission of aversive signals and motivational behavior across species. However, emerging evidence that will be 
explored here suggests important functional differences between the $\mathrm{LHb}$ and $\mathrm{RMTg}$ responsiveness to aversive stimuli and learning.

In contrast to the $\mathrm{LHb}$ projections to midbrain, the behavioral consequences of the neural activation of LHb afferents are less understood. The VTA sends rich projections to the LHb and plays a role in reward, motivation, learning, and aversion (Deutch and Roth, 1990; Roeper, 2013), which have been linked to release of DA in the LHb by the VTA afferents. However, contrary to this longstanding hypothesis, recent studies have found that these mesohabenular neurons do not release DA because they lack vesicular monoamine transporter 2 and cannot package DA inside synaptic vesicles (Root et al., 2015). These authors show that electrical stimulation of the LHb induces release of norepinephrine that can activate postsynaptic DA receptors in the LHb of rats and lead to the expression of reward phenotype. In addition, it has been shown in mice that optogenetic stimulation of VTA efferents to the LHb does not induce release of DA but instead causes release of GABA (Stamatakis et al., 2013), which suggests that the lack of a large pool of vesicular DA in the projections from VTA to LHb may be a common characteristic of rodent brain.

The heterogeneity in neuronal phenotypes of the VTA has been associated with VTA's diverse behavioral roles. For example, activation of VTA-GABA neurons is aversive (Tan et al., 2012), whereas activation of VTA-GABA afferents to LHb induces suppression of $\mathrm{LHb}$ firing and promotes reward-related behaviors (Stamatakis et al., 2013). Activation of VTA-VGluT2 neurons that innervate LHb (Hnasko et al., 2012) also elicits aversion (Root et al., 2014).

In addition to VTA afferents, the LHb receives major glutamatergic and GABAergic inputs from the globus pallidus interna (GPi), lateral hypothalamus (LH), basal forebrain, and ventral pallidum (Hong and Hikosaka, 2008; Shabel et al., 2012; Golden et al., 2016; Stamatakis et al., 2016). Neurons in the GPi and LH corelease glutamate and GABA as their neurotransmitters with the net effect that they can increase LHb firing when activated (Shabel et al., 2012, 2014; Stamatakis et al., 2016). In both cases, neurons in the LH and GPi are modulated by the cues that predict the availability of reward and aversion (Hong and Hikosaka, 2008; Bromberg-Martin et al., 2010) and can drive aversive behavior (Shabel et al., 2012; Stamatakis et al., 2016). Recent experiments have shown that shifted corelease of glutamate and GABA is a crucial mediator of aversive states, such as depression and cocaine withdrawal (Shabel et al., 2014; Meye et al., 2016).

In addition to representing signals associated with negative outcome, evidence is emerging to support the involvement of the $\mathrm{LHb}$ in goal-directed behaviors and behavioral flexibility (Kawai et al., 2015; Baker et al., 2016). Studies in nonhuman primates suggest that the anterior cingulate cortex (ACC) and the LHb both signal the negative outcome of choice and subsequently the adjustment of choice behaviors, albeit in distinct ways (Kawai et al., 2015). Although the nature of neural signals that reach the ACC is not known, these data suggest that the ACC and the LHb may act jointly to mediate information processing and decision making. Recent results from the LHb inactivation experiments in rodents (Baker et al., 2016), discussed in this review, may facilitate interpretation of findings from macaque studies and offer insight into the possible mechanisms by which the LHb registers ongoing states and determines appropriate behavioral response.

By bringing together findings from anatomical, molecular, physiological, and behavioral studies, this review seeks to explore in-depth critical components of the larger LHb circuits with emerging cross-species perspectives with a goal to formulate more refined hypotheses regarding the role of the $\mathrm{LHb}$ in complex behaviors. Because disturbances in the neural mechanisms involved in processing of positive and negative valence and cognition are common across mental and drug abuse disorders, detailed investigation of the role of the $\mathrm{LHb}$ in reward and aversion as well as behavioral flexibility should facilitate understanding of how the LHb dysfunctions may be implicated in these disorders.

\section{Dissecting the role of the habenula-projecting globus pallidus in behavioral reinforcement}

The ability to choose appropriate actions in the face of potential reward and punishment is essential for survival. Such behavioral choice is subserved by the brain reward circuitry encompassing the basal ganglia and the mesocorticolimbic dopamine system (Floresco et al., 2008; Graybiel, 2008). The LHb has recently emerged as a key nucleus in this circuitry (Lecourtier and Kelly, 2007; Proulx et al., 2014) as neurons in this nucleus are excited by the expectation of unpleasant events or when an outcome is worse than expected, and are inhibited by the expectation of reward or when an outcome is better than expected (Matsumoto and Hikosaka, 2007, 2009; Hong et al., 2011; Lawson et al., 2014). In other words, LHb neurons encode motivational values and PEs (Hikosaka, 2010; Proulx et al., 2014), in an opposite manner compared with dopamine neurons in the VTA and SNc (Schultz, 1998). Notably, activation of the LHb suppresses dopamine neurons via the inhibitory RMTg (Christoph et al., 1986; Ji and Shepard, 2007; Jhou et al., 2009a), and LHb lesions impair the PE signals in dopamine neurons (Tian and Uchida, 2015). These results suggest that the $\mathrm{LHb}$ provides, at least in part, the $\mathrm{PE}$ signals to dopamine neurons.

A major input to the $\mathrm{LHb}$ arises from the GPi, also called the entopeduncular nucleus in rodents (Rajakumar et al., 1993; Parent et al., 2001; Hong and Hikosaka, 2008). Neurons in the habenula-projecting globus pallidus, hereafter named as GPh, are distinct from the canonical GPi neurons. Whereas the latter population is inhibitory and controls motor function through projections to the brainstem and thalamic motor areas (Graybiel, 2008), the former uses glutamate as a major neurotransmitter (Shabel et al., 2012, 2014) and projects exclusively to the LHb (Rajakumar et al., 1993; Parent et al., 2001; Hong and Hikosaka, 2008; Stephenson-Jones et al., 2016). Interestingly, GPh neurons respond to reward and punishment, as well as the expectation of reward and punishment, in a manner similar to that of $\mathrm{LHb}$ neurons (Hong and Hikosaka, 2008, 2013). In addition, the response of GPh neurons precedes that of LHb neurons, and stimulation of the GPh area excites LHb neurons (Hong and Hikosaka, 2013). These findings indicate that the GPh may provide a major source of the value and PE signals to the LHb.

Recent studies have also examined the behavioral effects of $\mathrm{GPh}-\mathrm{LHb}$ circuit manipulations. Activation of neurons in the $\mathrm{GPh}-\mathrm{LHb}-\mathrm{VTA}$ pathway elicits aversive responses (Lammel et al., 2012; Shabel et al., 2012; Stamatakis and Stuber, 2012). These observations, together with the findings that both GPh (Hong and Hikosaka, 2008, 2013) and LHb (Matsumoto and Hikosaka, 2007, 2009; Hong et al., 2011; Lawson et al., 2014) neurons encode negative PE signals, have led to a prevailing hypothesis that the primary function of the GPh-LHb circuit is controlling aversive or negative motivational responses. However, this hypothesis was recently challenged as inhibition of the LHb prevented mice from forming a preference for large risky rewards over small certain rewards (Stopper and Floresco, 2014). This suggests that the LHb does not just carry the information about the cost of an 
a

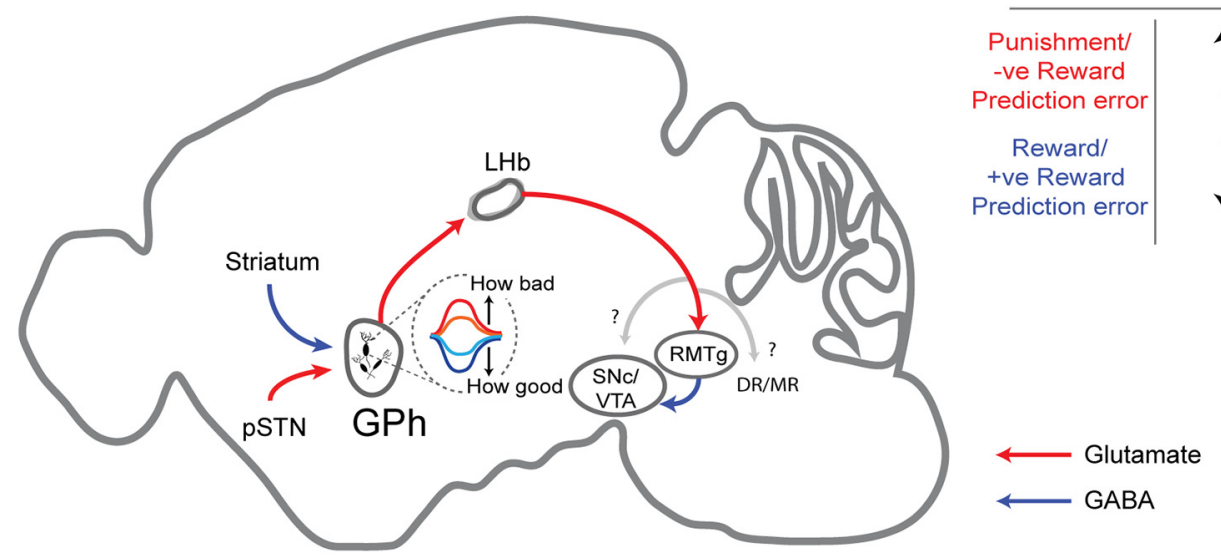

b

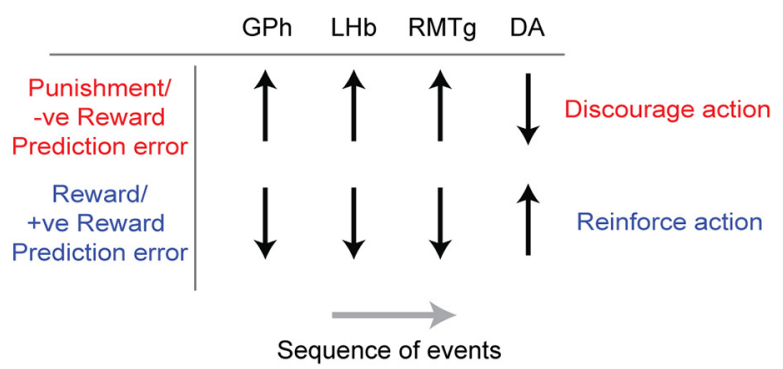

Figure 1. The proposed function of the basal ganglia and midbrain evaluation circuits. $\boldsymbol{a}$, Schematic showing the activity of GPh neurons and the downstream circuitry controlling the midbrain dopaminergic system. Modified from the Allen Mouse Brain Atlas, Allen Institute for Brain Science (available from http://mouse.brain-map.org/). Adapted from Stephenson-Jones et al. (2016). $\boldsymbol{b}$, Proposed sequence of events by which GPh activity may influence the firing rate in downstream structures. DR, Dorsal raphe; MR, median raphe; pSTN, parasubthalamic nucleus. Upward arrows, increase in firing; downward arrows, decrease in firing; ?, alternative circuits downstream of the LHb, including the serotonergic raphe nuclei, may constitute other key pathways that also process the GPh-LHb PE signals that we demonstrate in Stephenson-Jones et al., 2016.

action but rather contributes to the evaluation of both the cost and benefits of a given decision.

Information about the cost and benefit of a choice may arise from the GPh as recent in vivo recordings in mice have demonstrated that, as in primates (Hong and Hikosaka, 2008, 2013), GPh neurons signal both how good or how bad an outcome is through graded inhibition or excitation, respectively (Stephenson-Jones et al., 2016). These bidirectional signals have an opposing influence on reinforcement, as mimicking them with optogenetic inhibition or excitation can reinforce or discourage choices, respectively (Stephenson-Jones et al., 2016). Moreover, synapse-specific manipulations have recently revealed that excitation of the GPh is essential for discouraging unrewarded actions, whereas the inhibitory signals are essential for reinforcing rewarded outcomes (Stephenson-Jones et al., 2016). Consequently, the GPh does not just provide an aversive signal to the $\mathrm{LHb}$; rather, it is a key site where information of opposing valence is integrated to signal whether a decision was better or worse than expected.

The evaluation function of the GPh-LHb pathway is likely mediated through the bidirectional control of dopamine neurons. The GPh is well placed to bidirectionally influence dopaminergic activity as it provides tonic excitatory input to the LHb (Shabel et al., 2012; Stephenson-Jones et al., 2013; StephensonJones et al., 2016), which in turn regulates dopamine neurons (Ji and Shepard, 2007; Matsumoto and Hikosaka, 2007, 2009), disynaptically via the GABAergic RMTg (Jhou et al., 2009a; Hong et al., 2011). Indeed, bidirectional changes in LHb firing have opposing effects on motivation and dopaminergic firing, with activation of the $\mathrm{LHb}$ leading to aversion and a phasic decrease in dopamine (Ji and Shepard, 2007; Matsumoto and Hikosaka, 2007; Stamatakis and Stuber, 2012), whereas inhibition of the $\mathrm{LHb}$ is rewarding and leads to an increase in dopaminergic activity (Stamatakis et al., 2013). Furthermore, lesions of the LHb disrupt negative and impair positive reward PE coding in dopaminergic neurons (Tian and Uchida, 2015), which is critical for reinforcement learning. Consequently, we propose that an increase in GPh activity, when an outcome is worse than expected, increases the excitatory drive onto the LHb to inhibit dopamine neurons and discourage repeating the action, whereas decreases in GPh activity, when an outcome is better than expected, remove the tonic excitation of the LHb to increase dopaminergic activity and reinforce the choice (Fig. 1).

\section{Influence of GPh and lateral habenula on downstream structures}

Although the exact influences of the LHb on behavior are still being elucidated, a major part of this influence likely occurs via the LHb's powerful inhibitory influence on midbrain dopamine neurons by way of the RMTg (Jhou et al., 2009a, b; BalcitaPedicino et al., 2011; Hong et al., 2011). This opposing relationship between LHb and dopamine suggests an elegant symmetry between opposing motivational systems in the brain, as dopamine release is reinforcing (Tsai et al., 2009), whereas activation of LHb or RMTg is aversive (Stamatakis and Stuber, 2012; Jhou et al., 2013). Notably, drugs of abuse, such as cocaine, activate both of these opposing systems at different times. For example, single doses of cocaine initially increase dopamine levels but, after an $\sim 15$ min delay, begin to activate LHb neurons instead (Jhou et al., 2013). During the latter period, place preference studies show that the animal is actually in an aversive state, reflecting a postdrug "crash" (Ettenberg et al., 1999; Jhou et al., 2013). Furthermore, lesions of the $\mathrm{LHb}$, or optogenetic inactivation of the RMTg occurring 15-25 min after cocaine delivery, greatly impair avoidance conditioning driven by the aversive phase of cocaine. Additional studies from Mameli and colleagues further implicate $\mathrm{LHb}$ activation in longer-term cocaine-induced depressive-like states, as these states seem to depend on glutamate receptor trafficking in the LHb itself (Meye et al., 2015), as well as on synaptic changes in the balance of neurotransmitter signaling in GPh axons that corelease GABA and glutamate (Shabel et al., 2014; Meye et al., 2016). Hence, the functional connections from the GPh to $\mathrm{LHb}$ and then to RMTg may be involved in aversive effects of cocaine withdrawal and possibly other addictive drugs, such as opioids (Sanchez-Catalan et al., 2016). Notably, delayed aversive effects of drugs had previously been described in so-called "opponent process" models of motivation, which had been postulated decades earlier to describe the negative hedonic state of drug withdrawal (Solomon and Corbit, 1974; Koob et al., 1989), raising the possibility that one of the functions of the LHb and RMTg 
is to drive the negative affective states occurring during drug withdrawal.

Although the above studies imply that the LHb and RMTg function in tandem, a combination of anatomical, electrophysiological, and behavioral findings suggest that there are also major differences in function. In primates, a subset of RMTg neurons discriminate between rewarded and nonrewarded cues a few milliseconds earlier than the LHb, despite the RMTg neurons being downstream from the LHb (Hong et al., 2011). This finding is consistent with anatomic evidence that the RMTg receives multiple convergent inputs, not only from the $\mathrm{LHb}$, but also from structures such as cortex and extended amygdala, that likely carry information about motivationally relevant events (Jhou et al., 2009b; Kaufling et al., 2009; Gonçalves et al., 2012). This raises the question about how signals from the LHb are integrated into the larger networks of which it is a part. Different behaviors differ greatly in the degree to which they depend on either the LHb or RMTg. For example, as noted above, both RMTg and LHb inactivations greatly reduce conditioned aversive responses to cocaine. However, only RMTg lesions, and not LHb lesions, produce striking losses of freezing behavior in a conditioned fear paradigm (Heldt and Ressler, 2006; Jhou et al., 2009a). In addition, we have found that rats with RMTg lesions are highly resistant to punishment (i.e., will continue to seek rewards despite receiving large footshocks), whereas LHb lesioned rats are not different from fully intact rats (P.J. Vento et al., submitted). Hence, even though LHb activation appears sufficient to drive aversion, it is not always necessary. The exact reasons why some behaviors are more dependent on LHb function than others is unknown, and represents a major area of future inquiry. Given the wide distribution of afferents to the RMTg, considerable effort will be needed to determine which afferents are active at which times, and for what purposes. As will be detailed further in the following section, one area where the LHb may play a particular role is in the flexibility to drive behaviors that are different from ongoing or default behaviors. For example, it was noted above that LHb lesions do not abolish conditioned freezing in a fear paradigm. However, LHb lesions may abolish the enhancement of fear induced by isolation stress, without removing the baseline fear (Murphy et al., 1996), consistent with a role for the $\mathrm{LHb}$ in flexible adjustment of behavior beyond what is expected by default.

\section{The lateral habenula in behavioral flexibility}

$\mathrm{The} \mathrm{LHb}$ is interconnected with forebrain and midbrain areas required for working memory and behavioral flexibility performance (Baker et al., 2015; Quina et al., 2015), often regarded as the ability to switch behaviors when external contingencies change. Refinement of early lesion work and electrophysiological recording in freely behaving rodents suggests the LHb plays a broad role in behavioral flexibility. For example, the ability to reverse learned behaviors relies on an intact LHb in both appetitive and aversively motivated tasks (Nielson and McIver, 1966; Thornton and Evans, 1984; Thornton and Davies, 1991; Baker et al., 2016). Specifically, habenula lesioned rats trained to run to a maze arm and press a lever to end foot shock continue to enter the original arm when the lever contingencies are reversed (Nielson and McIver, 1966). When required to reverse behavior from one reward arm to the opposite to receive reinforcement on a t-maze, $\mathrm{LHb}$ inactivation resulted in increased trials to criterion that was marked by increased lose-shift and decreased win-stay behavior, suggesting that rats were no longer sensitive to reward outcomes when making arm choices (Baker et al., 2015). In a subsequent study, rats were also insensitive to cues that signaled the appropriate upcoming arm choice and instead engaged in an ineffective egocentric response strategy (Baker et al., 2016). In the Morris water maze task, inactivation or blockade of excitatory AMPA receptors within the LHb using CNQX resulted in impaired learning and retrieval, but not consolidation of a hidden platform location (Mathis et al., 2015). The rats engaged in thigmotaxis when either drug was injected, suggesting that rats may be engaging in default behavior, which would prevent them from effectively finding the platform and readily acquiring the task.

This deficit is not likely due to decreased motivation but rather an inability to engage in alternative strategies, as thigmotaxis represents an active attempt to escape from the water. A possible explanation for findings across both appetitive and aversive tasks is that the LHb is critical for overcoming default behavior to engage in either exploratory or alternative learned behaviors. Somewhat speculatively, this could also account for findings from optogenetic stimulation of LHb neurons, which resulted in active, passive, and conditioned avoidance behaviors in mice (Stamatakis and Stuber, 2012; but see Jhou et al., 2009a), in which passive defenses were selectively impaired over active ones after RMTg disruption in rats. Namely, activation of these neurons could spur animals to engage in nonspecific alternative behaviors, which manifest as avoidance of neural stimulation.

In vivo electrophysiological recordings can reveal the nature of neural computations during performance of behaviors (e.g., adaptive navigation) previously identified with lesion and pharmacological or optogenetic studies of the LHb. To date, few studies have examined neural correlates of behavior in unrestricted animals. Two such studies have identified LHb neurons in freely navigating rats that correlate with the speed of the animal (Sharp et al., 2006; Baker et al., 2015). These speed cells displayed stability across changing contexts (Baker et al., 2015), suggesting that the LHb provides ongoing behavioral state information that interacts with other signals related to changing environmental contexts. Similar context-insensitive speed neurons have been described in the entorhinal cortex, and these are thought to provide important behavioral information to an overall cognitive map needed for accurate navigation (Kropff et al., 2015). Similarly, speed cells in the LHb may provide a stable readout of behavior, which is integrated with task relevant cues, such as reward, punishment, or cues that can be used to guide behavior when the ongoing or default behavior is not the optimal choice. As of yet, the limited number of electrophysiological studies in unrestricted, freely navigating animals hampers attempts to create a comprehensive account of LHb function in behavioral flexibility.

Together, these results suggest that the LHb broadly contributes to strategy generation and/or response selection when alternative strategies or responses are required. The neural responses that contribute to strategy generation and response selection within the LHb, and how various input structures contribute to neural codes, remain key components of understanding the role of the LHb in behavioral flexibility.

\section{Negative reward signals in the lateral habenula regulate functions of the PFC}

The LHb may interact with the PFC, to regulate aspects of executive function. Because the $\mathrm{LHb}$ does not send projections to the PFC, its signals do not directly reach this region. However, the LHb is known to regulate the activity of monoaminergic cell groups, such as dopamine (Christoph et al., 1986; Ji and Shepard, 2007) and serotonin neurons (Wang and Aghajanian, 1977) that 
project to the PFC. Pharmacological inactivation of the LHb increases dopamine concentration in the PFC (Lecourtier et al., 2008). Thus, the LHb could affect processing in the PFC by transmitting its signals via monoaminergic cell groups. Consistent with this view, Lammel et al. (2012) reported that manipulation of signals transmitted from the LHb to the MPFC via dopamine neurons in the VTA alters an avoidance behavior in rodents. Using optogenetics, these authors demonstrated that phasic stimulation of the pathway from the LHb to the VTA in a conditioned place preference assay causes a strong conditioned place aversion. They also found that $\mathrm{LHb}$ neurons synapse primarily on dopamine neurons in the VTA projecting to the $\mathrm{mPFC}$ and that injection of a D1 dopamine receptor antagonist into the $\mathrm{mPFC}$ prevents the conditioned place aversion induced by the optogenetic stimulation of the LHb-VTA pathway. These findings suggest that $\mathrm{LHb}$ signals reach the MPFC via VTA dopamine neurons where they can affect information processing and cognitive functions mediated by this area.

As described above, the interaction of the LHb with the PFC seems to be important for regulating its functions. To address how these brain structures cooperate, Kawai et al. (2015) recently investigated what signals are shared and what roles are divided between the $\mathrm{LHb}$ and the PFC, especially a ventral part of the PFC called the ACC (Kawai et al., 2015). The ACC is known for its crucial roles in monitoring negative outcome (Ito et al., 2003; Quilodran et al., 2008) and adjusting behavior using the outcome information (Shima and Tanji, 1998; Williams et al., 2004). Kawai et al. (2015) recorded neuronal activity from the LHb and ACC in monkeys performing a reversal learning task in which choosing one of two options was followed by a liquid reward in a probabilistic manner while choosing the other option was followed by no reward. The reward contingency was frequently reversed without any instruction. To maximize reward gain, the monkey was required to store information about negative outcomes in several past trials and to use that information to adjust subsequent choice behavior. Their findings show that ACC neurons store outcome information from several past trials, whereas $\mathrm{LHb}$ neurons mainly represent current negative outcome with shorter latencies. Furthermore, ACC neurons, but not LHb neurons, signaled a behavioral adjustment after negative outcome experiences. These findings suggest that the LHb provides signals about ongoing negative outcome, whereas the ACC accumulates this outcome information across several past trials and uses this information to adjust subsequent choice behavior. Consistent with the idea that the ACC receives negative outcome information from the $\mathrm{LHb}$, dopamine neurons that mediate the LHb-ACC circuit interaction also encode negative outcome information by their inhibitory response. Such an inhibitory dopamine signal has been proposed to be transmitted to the ACC by disinhibiting ACC neurons (Holroyd and Coles, 2002). Indeed, pharmacological blockade of dopaminergic transmission reduces the event-related potential evoked by negative outcome in the ACC (Vezoli and Procyk, 2009). Together, LHb neurons might transmit negative outcome signals via dopamine neurons to the ACC that acts as a source of the outcome information accumulated across trials. Further studies will determine the causal relationship between the LHb and ACC signals and their role in performance monitoring.

In conclusion, recent discoveries from rodents and nonhuman primate studies implicate the LHb circuits in the encoding of motivational values and PEs, which are critical signals for learning and flexible decision making when faced with potential reward and/or punishment. Although the detailed mechanisms that underlie the role of $\mathrm{LHb}$ in these behaviors still remain unclear, the findings described above support a conceptual framework where, through distinct neural populations and synaptic connections, the LHb inputs and outputs act both cooperatively and distinctively to guide complex behaviors. The studies that examined the role of LHb-RMTg circuits in aversive behaviors suggest that these regions may act both synergistically and distinctively to drive negative affective states. Given that RMTg also receives inputs from other brain regions that exhibit rewarddependent modulation, this could account for temporal differences in LHb and RMTg activity and in representation of state value. Moreover, the GPh-LHb circuits play a role not only in representation of negative motivational valence or promotion of aversive responses, but also in the evaluation of positive and negative outcomes, which are the bases of flexible decision making. The results from nonhuman primate studies are congruent with the notion that the LHb plays a role in decision making, possibly by acting as a source of neural signal necessary for the prefrontal brain areas, such as ACC, to signal behavioral adjustments following negative or positive outcome experiences. Recent studies in rodents further reveal that a specific population of cells within the $\mathrm{LHb}$ represents the information relevant to ongoing behavior that is not linked to reward specific responses. These data suggest that the LHb tracks the current behavioral state of the animal to inform action selection within a given context. Together, these results suggest that neural heterogeneity within the LHb serves as a source of diversity of behavioral phenotypes associated with this circuit. These findings also raise open questions about the cellular identity and anatomical connectivity of cellular ensembles that play a role in cognition and positive and negative valence that need to be investigated more extensively.

An additional open question for lateral habenula research is whether neural signals that play a role in learning develop stable patterns of activity over the course of learning or whether the neural code remains relatively stable from naive to stable behavior. Thus far, evidence suggests that individual neurons and theta power of local field potentials remain relatively stable when environmental or reward contingencies change (e.g., light to dark or reward omission) (Baker et al., 2015). This seems to contrast with evidence suggesting that the LHb is important for performing learned behaviors or switching between behavior (Stopper and Floresco, 2014; Baker et al., 2016). It may be that population ensembles order themselves in unique ways under learned contexts to provide efferent connections of the specific context of the animal as is seen in prefrontal cortical areas (Kobak et al., 2016; $\mathrm{Ma}$ et al., 2016). Ongoing experiments are attempting to address this possibility.

Future studies using cell type- and projection-specific manipulations, electrophysiological recordings, and new methods to study signaling dynamics should aid in better understanding of the nature of neural computations in the LHb circuit that guide cognitive functions and reward and aversive-related behaviors. Given that learning about what predicts rewarding or aversive outcomes is adaptive, studies addressing molecular, cellular, and circuit properties of the $\mathrm{LHb}$ circuits will offer insights into the mechanisms underlying dysfunctions of these domains in mental disorders and drug addiction ultimately guiding the development of more effective treatments.

\section{References}

Baker PM, Oh SE, Kidder KS, Mizumori SJ (2015) Ongoing behavioral state information signaled in the lateral habenula guides choice flexibility in freely moving rats. Front Behav Neurosci 9:295. CrossRef Medline 
Baker PM, Raynor SA, Francis NT, Mizumori SJ (2016) Lateral habenula integration of proactive and retroactive information mediates behavioral flexibility. Neuroscience. Advance online publication. Retrieved Feb. 10, 2016. doi: 10.1016/j.neuroscience.2016.02.010. CrossRef Medline

Balcita-Pedicino JJ, Omelchenko N, Bell R, Sesack SR (2011) The inhibitory influence of the lateral habenula on midbrain dopamine cells: ultrastructural evidence for indirect mediation via the rostromedial mesopontine tegmental nucleus. J Comp Neurol 519:1143-1164. CrossRef Medline

Bromberg-Martin ES, Matsumoto M, Hong S, Hikosaka O (2010) A pallidus-habenula-dopamine pathway signals inferred stimulus values. J Neurophysiol 104:1068-1076. CrossRef Medline

Christoph GR, Leonzio RJ, Wilcox KS (1986) Stimulation of the lateral habenula inhibits dopamine-containing neurons in the substantia nigra and ventral tegmental area of the rat. J Neurosci 6:613-619. Medline

Deutch AY, Roth RH (1990) The determinants of stress-induced activation of the prefrontal cortical dopamine system. Prog Brain Res 85:367-402; discussion 402-403. Medline

Ettenberg A, Raven MA, Danluck DA, Necessary BD (1999) Evidence for opponent-process actions of intravenous cocaine. Pharmacol Biochem Behav 64:507-512. CrossRef Medline

Floresco SB, St Onge JR, Ghods-Sharifi S, Winstanley CA (2008) Corticolimbic-striatal circuits subserving different forms of cost-benefit decision making. Cogn Affect Behav Neurosci 8:375-389. CrossRef Medline

Golden SA, Heshmati M, Flanigan M, Christoffel DJ, Guise K, Pfau ML, Aleyasin H, Menard C, Zhang H, Hodes GE, Bregman D, Khibnik L, Tai J, Rebusi N, Krawitz B, Chaudhury D, Walsh JJ, Han MH, Shapiro ML, Russo SJ (2016) Basal forebrain projections to the lateral habenula modulate aggression reward. Nature 534:688-692. CrossRef Medline

Gonçalves L, Sego C, Metzger M (2012) Differential projections from the lateral habenula to the rostromedial tegmental nucleus and ventral tegmental area in the rat. J Comp Neurol 520:1278-1300. CrossRef Medline

Graybiel AM (2008) Habits, rituals, and the evaluative brain. Annu Rev Neurosci 31:359-387. CrossRef Medline

Heldt SA, Ressler KJ (2006) Lesions of the habenula produce stress- and dopamine-dependent alterations in prepulse inhibition and locomotion. Brain Res 1073:229-239. CrossRef Medline

Hikosaka O (2010) The habenula: from stress evasion to value-based decision-making. Nat Rev Neurosci 11:503-513. CrossRef Medline

Hikosaka O, Sesack SR, Lecourtier L, Shepard PD (2008) Habenula: crossroad between the basal ganglia and the limbic system. J Neurosci 28: 11825-11829. CrossRef Medline

Hnasko TS, Hjelmstad GO, Fields HL, Edwards RH (2012) Ventral tegmental area glutamate neurons: electrophysiological properties and projections. J Neurosci 32:15076-15085. CrossRef Medline

Holroyd CB, Coles MG (2002) The neural basis of human error processing: reinforcement learning, dopamine, and the error-related negativity. Psychol Rev 109:679-709. CrossRef Medline

Hong S, Hikosaka O (2008) The globus pallidus sends reward-related signals to the lateral habenula. Neuron 60:720-729. CrossRef Medline

Hong S, Hikosaka O (2013) Diverse sources of reward value signals in the basal ganglia nuclei transmitted to the lateral habenula in the monkey. Front Hum Neurosci 7:778. CrossRef Medline

Hong S, Jhou TC, Smith M, Saleem KS, Hikosaka O (2011) Negative reward signals from the lateral habenula to dopamine neurons are mediated by rostromedial tegmental nucleus in primates. J Neurosci 31:11457-11471. CrossRef Medline

Ito S, Stuphorn V, Brown JW, Schall JD (2003) Performance monitoring by the anterior cingulate cortex during saccade countermanding. Science 302:120-122. CrossRef Medline

Jhou TC, Fields HL, Baxter MG, Saper CB, Holland PC (2009a) The rostromedial tegmental nucleus (RMTg), a GABAergic afferent to midbrain dopamine neurons, encodes aversive stimuli and inhibits motor responses. Neuron 61:786-800. CrossRef Medline

Jhou TC, Geisler S, Marinelli M, Degarmo BA, Zahm DS (2009b) The mesopontine rostromedial tegmental nucleus: a structure targeted by the lateral habenula that projects to the ventral tegmental area of Tsai and substantia nigra compacta. J Comp Neurol 513:566-596. CrossRef Medline

Jhou TC, Good CH, Rowley CS, Xu SP, Wang H, Burnham NW, Hoffman AF, Lupica CR, Ikemoto S (2013) Cocaine drives aversive conditioning via delayed activation of dopamine-responsive habenular and midbrain pathways. J Neurosci 33:7501-7512. CrossRef Medline
Ji H, Shepard PD (2007) Lateral habenula stimulation inhibits rat midbrain dopamine neurons through a GABA(A) receptor-mediated mechanism. J Neurosci 27:6923-6930. CrossRef Medline

Kaufling J, Veinante P, Pawlowski SA, Freund-Mercier MJ, Barrot M (2009) Afferents to the GABAergic tail of the ventral tegmental area in the rat. J Comp Neurol 513:597-621. CrossRef Medline

Kawai T, Yamada H, Sato N, Takada M, Matsumoto M (2015) Roles of the lateral habenula and anterior cingulate cortex in negative outcome monitoring and behavioral adjustment in nonhuman primates. Neuron 88 : 792-804. CrossRef Medline

Kim U, Lee T (2012) Topography of descending projections from anterior insular and medial prefrontal regions to the lateral habenula of the epithalamus in the rat. Eur J Neurosci 35:1253-1269. CrossRef Medline

Kobak D, Brendel W, Constantinidis C, Feierstein CE, Kepecs A, Mainen ZF, Qi XL, Romo R, Uchida N, Machens CK (2016) Demixed principal component analysis of neural population data. eLife 5:e10989. CrossRef Medline

Koob GF, Stinus L, Le Moal M, Bloom FE (1989) Opponent process theory of motivation: neurobiological evidence from studies of opiate dependence. Neurosci Biobehav Rev 13:135-140. CrossRef Medline

Kropff E, Carmichael JE, Moser MB, Moser EI (2015) Speed cells in the medial entorhinal cortex. Nature 523:419-424. CrossRef Medline

Lammel S, Lim BK, Ran C, Huang KW, Betley MJ, Tye KM, Deisseroth K, Malenka RC (2012) Input-specific control of reward and aversion in the ventral tegmental area. Nature 491:212-217. CrossRef Medline

Lawson RP, Seymour B, Loh E, Lutti A, Dolan RJ, Dayan P, Weiskopf N, Roiser JP (2014) The habenula encodes negative motivational value associated with primary punishment in humans. Proc Natl Acad Sci U S A 111:11858-11863. CrossRef Medline

Lecourtier L, Kelly PH (2007) A conductor hidden in the orchestra? Role of the habenular complex in monoamine transmission and cognition. Neurosci Biobehav Rev 31:658-672. CrossRef Medline

Lecourtier L, Defrancesco A, Moghaddam B (2008) Differential tonic influence of lateral habenula on prefrontal cortex and nucleus accumbens dopamine release. Eur J Neurosci 27:1755-1762. CrossRef Medline

Ma L, Hyman JM, Durstewitz D, Phillips AG, Seamans JK (2016) A quantitative analysis of context-dependent remapping of medial frontal cortex neurons and ensembles. J Neurosci 36:8258-8272. CrossRef Medline

Mathis V, Cosquer B, Avallone M, Cassel JC, Lecourtier L (2015) Excitatory transmission to the lateral habenula is critical for encoding and retrieval of spatial memory. Neuropsychopharmacology 40:2843-2851. CrossRef Medline

Matsumoto M, Hikosaka O (2007) Lateral habenula as a source of negative reward signals in dopamine neurons. Nature 447:1111-1115. CrossRef Medline

Matsumoto M, Hikosaka O (2009) Representation of negative motivational value in the primate lateral habenula. Nat Neurosci 12:77-84. CrossRef Medline

Meye FJ, Valentinova K, Lecca S, Marion-Poll L, Maroteaux MJ, Musardo S, Moutkine I, Gardoni F, Huganir RL, Georges F, Mameli M (2015) Cocaine-evoked negative symptoms require AMPA receptor trafficking in the lateral habenula. Nat Neurosci 18:376-378. CrossRef Medline

Meye FJ, Soiza-Reilly M, Smit T, Diana MA, Schwarz MK, Mameli M (2016) Shifted pallidal co-release of GABA and glutamate in habenula drives cocaine withdrawal and relapse. Nat Neurosci 19:1019-1024. CrossRef Medline

Murphy CA, DiCamillo AM, Haun F, Murray M (1996) Lesion of the habenular efferent pathway produces anxiety and locomotor hyperactivity in rats: a comparison of the effects of neonatal and adult lesions. Behav Brain Res 81:43-52. CrossRef Medline

Nielson HC, McIver AH (1966) Cold stress and habenular lesion effects on rat behaviors. J Appl Physiol 21:655-660. Medline

Parent M, Lévesque M, Parent A (2001) Two types of projection neurons in the internal pallidum of primates: single-axon tracing and threedimensional reconstruction. J Comp Neurol 439:162-175. CrossRef Medline

Proulx CD, Hikosaka O, Malinow R (2014) Reward processing by the lateral habenula in normal and depressive behaviors. Nat Neurosci 17:11461152. CrossRef Medline

Quilodran R, Rothé M, Procyk E (2008) Behavioral shifts and action valuation in the anterior cingulate cortex. Neuron 57:314-325. CrossRef Medline 
Quina LA, Tempest L, Ng L, Harris JA, Ferguson S, Jhou TC, Turner EE (2015) Efferent pathways of the mouse lateral habenula. J Comp Neurol 523:32-60. CrossRef Medline

Rajakumar N, Elisevich K, Flumerfelt BA (1993) Compartmental origin of the striato-entopeduncular projection in the rat. J Comp Neurol 331: 286-296. CrossRef Medline

Roeper J (2013) Dissecting the diversity of midbrain dopamine neurons. Trends Neurosci 36:336-342. CrossRef Medline

Root DH, Mejias-Aponte CA, Qi J, Morales M (2014) Role of glutamatergic projections from ventral tegmental area to lateral habenula in aversive conditioning. J Neurosci 34:13906-13910. CrossRef Medline

Root DH, Hoffman AF, Good CH, Zhang S, Gigante E, Lupica CR, Morales M (2015) Norepinephrine activates dopamine D4 receptors in the rat lateral habenula. J Neurosci 35:3460-3469. CrossRef Medline

Sanchez-Catalan MJ, Faivre F, Yalcin I, Muller MA, Massotte D, Majchrzak M, Barrot M (2016) Response of the tail of the ventral tegmental area to aversive stimuli. Neuropsychopharmacology. Advance online publication. Retrieved Aug. 31, 2016. doi: 10.1038/npp.2016.139. CrossRef Medline

Schultz W (1998) Predictive reward signal of dopamine neurons. J Neurophysiol 80:1-27. Medline

Shabel SJ, Proulx CD, Trias A, Murphy RT, Malinow R (2012) Input to the lateral habenula from the basal ganglia is excitatory, aversive, and suppressed by serotonin. Neuron 74:475-481. CrossRef Medline

Shabel SJ, Proulx CD, Piriz J, Malinow R (2014) Mood regulation. GABA/ glutamate co-release controls habenula output and is modified by antidepressant treatment. Science 345:1494-1498. CrossRef Medline

Sharp PE, Turner-Williams S, Tuttle S (2006) Movement-related correlates of single cell activity in the interpeduncular nucleus and habenula of the rat during a pellet-chasing task. Behav Brain Res 166:55-70. CrossRef Medline

Shima K, Tanji J (1998) Role for cingulate motor area cells in voluntary movement selection based on reward. Science 282:1335-1338. CrossRef Medline

Solomon RL, Corbit JD (1974) An opponent-process theory of motivation: I. Temporal dynamics of affect. Psychol Rev 81:119-145. CrossRef Medline

Stamatakis AM, Stuber GD (2012) Activation of lateral habenula inputs to the ventral midbrain promotes behavioral avoidance. Nat Neurosci 15: 1105-1107. CrossRef Medline

Stamatakis AM, Jennings JH, Ung RL, Blair GA, Weinberg RJ, Neve RL, Boyce F, Mattis J, Ramakrishnan C, Deisseroth K, Stuber GD (2013) A unique population of ventral tegmental area neurons inhibits the lateral habenula to promote reward. Neuron 80:1039-1053. CrossRef Medline
Stamatakis AM, Van Swieten M, Basiri ML, Blair GA, Kantak P, Stuber GD (2016) Lateral hypothalamic area glutamatergic neurons and their projections to the lateral habenula regulate feeding and reward. J Neurosci 36:302-311. CrossRef Medline

Stephenson-Jones M, Kardamakis AA, Robertson B, Grillner S (2013) Independent circuits in the basal ganglia for the evaluation and selection of actions. Proc Natl Acad Sci U S A 110:E3670-E3679. CrossRef Medline

Stephenson-Jones M, Yu K, Ahrens S, Tucciarone J, van Huijstee AN, Mejia LA, Penzo MA, Tai LH, Wilbrecht L, Li B (2016) A basal ganglia circuit for evaluating action outcomes. Nature. Advance online publication. Retrieved Sep. 21, 2016. doi: 10.1038/nature19845. CrossRef Medline

Stopper CM, Floresco SB (2014) What's better for me? Fundamental role for lateral habenula in promoting subjective decision biases. Nat Neurosci 17:33-35. CrossRef Medline

Tan KR, Yvon C, Turiault M, Mirzabekov JJ, Doehner J, Labouèbe G, Deisseroth K, Tye KM, Lüscher C (2012) GABA neurons of the VTA drive conditioned place aversion. Neuron 73:1173-1183. CrossRef Medline

Thornton EW, Davies C (1991) A water-maze discrimination learning deficit in the rat following lesion of the habenula. Physiol Behav 49:819-822. CrossRef Medline

Thornton EW, Evans JA (1984) The effects of lesions of the habenula nucleus on lever press behaviour during a tandem operant schedule with contrasting response requirements. Behav Brain Res 12:327-334. CrossRef Medline

Tian J, Uchida N (2015) Habenula lesions reveal that multiple mechanisms underlie dopamine prediction errors. Neuron 87:1304-1316. CrossRef Medline

Tsai HC, Zhang F, Adamantidis A, Stuber GD, Bonci A, de Lecea L, Deisseroth K (2009) Phasic firing in dopaminergic neurons is sufficient for behavioral conditioning. Science 324:1080-1084. CrossRef Medline

Vezoli J, Procyk E (2009) Frontal feedback-related potentials in nonhuman primates: modulation during learning and under haloperidol. J Neurosci 29:15675-15683. CrossRef Medline

Wang RY, Aghajanian GK (1977) Physiological evidence for habenula as major link between forebrain and midbrain raphe. Science 197:89-91. CrossRef Medline

Williams ZM, Bush G, Rauch SL, Cosgrove GR, Eskandar EN (2004) Human anterior cingulate neurons and the integration of monetary reward with motor responses. Nat Neurosci 7:1370-1375. CrossRef Medline

Zhao H, Zhang BL, Yang SJ, Rusak B (2015) The role of lateral habenuladorsal raphe nucleus circuits in higher brain functions and psychiatric illness. Behav Brain Res 277:89-98. CrossRef Medline 